\title{
CHARACTERIZATION OF URINARY STEROIDS IN ADRENAL HYPERPLASIA : ISOLATION OF METABOLITES OF CORTI- SOL, COMPOUND S, AND DESOXYCORTICOSTERONE FROM A NORMOTENSIVE PATIENT WITH ADRENOGENITAL SYNDROME *
}

\author{
By HORTENSE M. GANDY, $\dagger$ E. HENRY KEUTMANN AND ANTHONY J. IZZO \\ (From the Department of Medicine, the University of Rochester, School of Medicine and \\ Dentistry, Rochester, $N . Y$.)
}

(Submitted for publication August 25, 1958; accepted October 8, 1959)

Congenital virilizing adrenal hyperplasia may present a varied clinical picture. Patients have been described who have only excessive virilization (1) ; others have an associated Addison-like electrolyte disturbance $(2,3)$, with hypoglycemia (4), or with hypertension (5-9). Recent studies (1012 ) indicate that the manifestation of virilism may result from defects in the biosynthesis of cortisol. ${ }^{1}$ The first suggestion regarding the nature of the error was made by Lewis and Wilkins (12), and

* This study was supported by a grant (C-1003) from the National Cancer Institute, Bethesda, Md.

$\dagger$ Postdoctoral Research Fellow, United States Public Health Service. Present address: New York Hospital, New York, N. Y.

1 The following trivial names are used in the text: Hydrocortisone (Compound F) is $11 \beta, 17 \alpha, 21$-trihydroxy4-pregnene-3,20-dione. Tetrahydrocortisol (tetrahydro F) is $3 \alpha, 11 \beta, 17 \alpha, 21$-tetrahydroxy-pregnane-20-one. Cortisone (Compound $\mathrm{E}$ ) is $17 \alpha, 21$-dihydroxy-4-pregnene-3,11,20 -trione. Tetrahydrocortisone (tetrahydro $\mathrm{E}$ ) is $3 \alpha, 17 \alpha$, 21-trihydroxy-pregnane-11,20-dione. 11-Desoxyhydrocortisone (Compound S) is $17 \alpha, 21$-dihydroxy-4-pregnene-3,20-dione. Tetrahydro $\mathrm{S}$ is $3 \alpha, 17 \alpha, 21$-trihydroxy-pregnane-20-one. Dihydro $\mathrm{S}$ is $17 \alpha, 21$-dihydroxy-pregnane3,20-dione. Corticosterone (Compound B) is $11 \beta, 21$-dihydroxy-4-pregnene-3,20-dione. Tetrahydrocorticosterone (tetrahydro B) is $3 \alpha, 11 \beta, 21$-trihydroxy-pregnane-20-one. Desoxycorticosterone (DOC) is 21-hydroxy-4-pregnene3,20-dione. Tetrahydrodesoxycorticosterone is $3 \alpha, 21$-dihydroxy-pregnane-20-one. Dihydrodesoxycorticosterone is 21-hydroxy-pregnane-3,20-dione. Allo-dihydrodesoxycorticosterone acetate is 21 acetoxy-allo-pregnane-3,20-dione. Twenty-one desoxycortisone is $17 \alpha$-hydroxy-4-pregnene-3,-

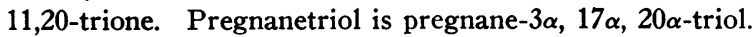
Pregnanediol is pregnane-3 $\alpha, 20 \alpha$-diol. Androsterone is $3 \alpha$-hydroxyandrostane-17-one. Etiocholanolone is $3 \alpha$-hydroxy-etiocholane-17-one. 11-Keto androsterone is $3 \alpha$-hydroxy-androstane-11,17-dione. 11 Ketoetiocholanolone is $3 \alpha$-hydroxy-etiocholane-11,17-dione. 11 Hydroxyandrosterone is $3 \alpha, 11 \beta$-dihydroxy-androstane-17-one. $11 \mathrm{Hy}-$ droxyetiocholanolone is $3 \alpha, 11 \beta$-dihydroxy-etiocholane-17one. corroborated by Bartter and associates (13). Dorfman (14) postulated that there is a deficiency in the C-21 hydroxylation mechanism. Eberlein and Bongiovanni (15) then found that some patients with congenital virilizing adrenal hyperplasia excreted C-21 hydroxylated compounds in approximately the same quantities as did normal individuals. Tetrahydrocortisone in small amounts was found. The present authors (16) have studied six patients with virilizing adrenal hyperplasia in addition to the one reported here. Each of these was found to be excreting C-21 hydroxylated compounds in amounts equal to those found in normals of comparable age. Tetrahydrocortisol was one of the $\alpha$-ketols present. More recently, both tetrahydrocortisone and tetrahydrocortisol have been found in the urine of patients with this disorder (17-20).

Abnormally high excretion of precursors of cortisol, metabolites of precursors, and androgens are well recognized consequences of the derangement in the pathway for synthesis of normal corticosteroids. Further augmentation of the amounts of such products is to be expected from the overstimulation by excess corticotropin. The identification of some of the abnormal metabolites has led to the clarification of the probable location of the errors in the synthetic process (7-22). Laboratory and clinical data reported by many workers favor the concept that the defect in some cases may be at two or more steps of the steroid synthesis.

Eberlein and Bongiovanni (7-9) studied an untreated patient who had congenital adrenal hyperplasia associated with hypertension. The plasma and urinary 17-hydroxycorticosteroids were markedly elevated. The plasma contained Compound S and tetrahydro S. The predominant compound in 
the urine was tetrahydro S. Tetrahydrodesoxycorticosterone was also identified.

Three nonketonic $C_{21}$ steroids and two $C_{19}-17$ ketosteroids were isolated and identified by infrared spectroscopy. None of the compounds isolated had oxygen functions at the 11-carbon. The authors proposed that these findings were evidence for deficiency in C-11 hydroxylation. They also suggested that the hypertension may be attributed to accumulation of desoxycorticosterone, and this type of defect has been considered characteristic of congenital adrenal hyperplasia when hypertension is a complication (21).

Later Dyrenfurth and associates (19) reported finding large amounts of tetrahydro $S$ in the urine of two patients with congenital adrenal hyperplasia: one had hypertension and the other did not. Both of them excreted metabolites of cortisol. More recently Birke and colleagues (20) studied the steroid patterns in the urine of two siblings with congenital adrenal hyperplasia. Both patients excreted tetrahydro $\mathrm{S}$, tetrahydrocortisone and 11-oxygenated 17-ketosteroids. Neither patient had hypertension.

The study reported here concerns a normotensive patient with the adrenogenital syndrome with a corticoid pattern characterized by the presence of the metabolites of Compound S and of desoxycorticosterone as well as of cortisol.

\section{CASE REPORT}

D.G., a white male, was first seen at 5.5 years of age when he was admitted to the Pediatric Service of this hospital for evaluation of sexual precocity. The parents related that he weighed $3.5 \mathrm{~kg}$ at birth. Acceleration of growth was noted during the first year of life. At 3 months the patient weighed $4.6 \mathrm{~kg}$, at 6 months $9.6 \mathrm{~kg}$, and at 10.5 months $12.0 \mathrm{~kg}$. Acne was noted on his face and chest at one year of age. The history was not remarkable otherwise.

On admission the patient had the physical development of an adolescent; his voice was deeply pitched. A papular rash was present on the face and over the shoulders. There was a moderate amount of hair on the upper lip and in the axillae; pubic hair was abundant. He weighed $35 \mathrm{~kg}$; his height was $142 \mathrm{~cm}$.

The blood pressure was recorded by 3 different examiners to be $100 / 65,105 / 70$ and $120 / 80$, respectively. Numerous other observers always found it to be within these limits. After 3 years' treatment with cortisone, the drug was discontinued for 2 weeks. At the end of this time the blood pressure was again found to be normal. The other remarkable features of the physical ex- amination were limited to a penis measuring $9 \mathrm{~cm}$ in length and small testes and prostate. The bone age, according to Todd's "Atlas of Skeletal Maturation," corresponded to that of 11 years and 9 months. The neutral 17-ketosteroids ranged from 15.7 to $21.7 \mathrm{mg}$ per day for 4 successive days before this investigation began. Urinary $\alpha$-ketol excretion, measured as blue tetrazolium reducing substances (23), ranged from 18.6 to $27.7 \mathrm{mg}$ per 24 hours. The normal range for children 5 to 7 years of age was found to be 2.5 to $3.5 \mathrm{mg}$ per 24 hours in our laboratory. Excretion of pregnanetriol and pregnanediol, determined according to the method of Bongiovanni (24) was 4.5 and $1.5 \mathrm{mg}$ per day, respectively. Serum electrolytes, hemogram, blood sugar and urinalysis were normal.

One week after the administration of $25 \mathrm{mg}$ of cortisone acetate orally every 12 hours, the urinary neutral 17 ketosteroid excretion and total corticoid excretion had decreased to 2.5 and $12.4 \mathrm{mg}$ per 24 hours, respectively. The excretion of both types of steroids rose to pretreatment levels 48 hours after the cortisone was discontinued. The patient was then placed on $37.5 \mathrm{mg}$ of cortisone orally per day in divided doses for the next 9 months. During that time the 17-ketosteroid excretion ranged between 1.2 and $2.5 \mathrm{mg}$ per 24 hours. Urinary pregnanetriol and pregnanediol were found to be 1.7 and $0.8 \mathrm{mg}$, respectively, per day. No change in the range of systolic or diastolic blood pressure was noted during the trial of cortisone, when the drug was stopped, or during maintenance therapy.

\section{METHODS}

Corticosteroids. A 3 day pool of urine was collected before treatment and again a week after cortisone therapy had been started. Twenty-four hour aliquots from each pool were buffered at $\mathrm{pH} 4.8$, hydrolyzed for 48 hours at $47^{\circ} \mathrm{C}$ with $\beta$-glucuronidase (250 units per $\mathrm{ml}$ of urine), and then continuously extracted with ether for 48 hours after the $\mathrm{pH}$ had been readjusted to 6.8. The extracted urine was put aside and the ether extracts were dried and washed in chloroform by the procedure described by Burton, Zaffaroni and Keutmann (25). The number of washings was reduced to 3 alkali, 1 acid, and 1 water wash, together with their appropriate back washings. Preliminary fractionation and identification were done on one of the 24 hour aliquots, the other two were used for more definite and confirmatory information both as to identity and quantitation.

The total $\alpha$-ketol content of the neutral extracts was measured with blue tetrazolium according to the method described by Izzo, Keutmann and Burton (23) prior to and after chromatographic fractionation on paper. The total C-21, 17-hydroxyglycol content was determined by the method of Wilson and Fairbanks (26), and total 17ketosteroid content by the method of Talbot, Berman and MacLachlan (27), using alcoholic $\mathrm{KOH}$ prepared according to Wilson and Carter (28). The amounts of the individual fractions or compounds were determined on known aliquots of eluates from the paper after the compound had been located with the appropriate spotting 
reagent. Quantities of individual compounds other than the above types were quantitated by methods which will be indicated in each instance. In order to insure against loss of $\alpha$-ketols, no preliminary separation into various types of the steroids in this extract was attempted. During treatment with Girard's reagent $T$, for instance, losses have been encountered by ourselves and other investigators $(29,30)$. The direct chromatography presented some problems, of course, when $\alpha$-ketols and glycols or other steroids with similar or identical running rates were found in greatly differing amounts on the same chromatograms. Separation was then accomplished by rechromatographing the area with different systems, different amounts, or by acetylation and subsequent chromatography.

Fractionation of each urine extract by paper chromatography was similar to that described by Burton and colleagues (25) with certain modifications as indicated in Figure 1. The neutral extract was applied to washed Whatman no. 1 filter paper impregnated with freshly prepared 50 per cent solution, by volume, of formamide in absolute methanol. The chromatograms were developed in the benzene/formamide system for 48 hours so as to yield 3 fractions consisting essentially of $\mathrm{C}_{21} \mathrm{O}_{3}$ (Fraction A), $\mathrm{C}_{21} \mathrm{O}_{4}$ (Fraction $\mathrm{B}$ ), and $\mathrm{C}_{21} \mathrm{O}_{5}$ (Fraction $\mathrm{C}$ ) compounds, respectively.

The steroids remaining on the paper as Fraction $C$ were eluted off with methanol. This eluate was rechromatographed in the toluene/propylene glycol system for 44 hours. The chromatogram was dried and examined under a fluoroscopic scanner (31). Reference strips 0.25 $\mathrm{cm}$ wide were cut from the center of the chromatogram and the steroids were located with the following: aqueous blue tetrazolium ; 2,4 dinitrophenylhydrazine (32) ; methanolic sodium hydroxide (33); the Zimmermann reaction using aqueous $\mathrm{KOH}$; periodic acid oxidation followed by the Zimmermann reaction (34) ; aqueous iodine (35); and sulfuric acid fluorescence. In certain instances additional spot tests were used to help in the location and identification, namely, treatment with phosphomolybdic acid (36) ; treatment with 70 per cent phosphoric acid $(37,38)$; and treatment with trichloracetic acid (39).

The reference strips treated with blue tetrazolium indicated that the $\alpha$-ketols were grouped in 3 zones at this time as illustrated in Figure 1. These were eluted separately and designated as subfractions $C-1, C-2$ and $C-3$ (Figure 1 and Table I). Fractions $A$ and $B$ were rechromatographed in the cyclohexane/formamide and the benzene/formamide systems, respectively, as indicated in Figure 1. Steroids were located on reference strips from each of these chromatograms with the group-specific spotting reagents enumerated above. Just as had been done with Fraction $\mathrm{C}$, these chromatograms were divided into subfractions corresponding to blue tetrazolium reactive zones.

The eluates of each of these were rechromatographed in the appropriate systems (Figure 1). In many instances it was necessary to rechromatograph a subfraction or an isolated steroid several times in order to achieve separa- tion of two different group-specific reacting areas or to eliminate urinary pigments. Complete separation was at times not achieved until acetates were made and chromatographed (35). This was especially true for mixtures of $\alpha$-ketols and other C-21 compounds which had the same mobility. These mixtures were separated most efficiently when undiluted formamide was used as the stationary phase.

Characterization was attempted in the case of each isolated steroid. The criteria for identification were: a) the chromatographic mobility in the free state and as acetates compared with authentic compounds and their acetates ; $b$ ) reactions of the unknown compounds on paper with the aforementioned group-specific reagents; $c$ ) the absorption spectra in methanol and sulfuric acid, respectively (40); and in most instances, $d$ ) infrared absorption spectra. Well defined spectra were obtained when the acetates either were partitioned between purified ethyl ether and ice water, or were passed through a micro-column of silica gel, or both.

Non- $\alpha$-ketolic C-21 steroids. These steroids were located on the toluene/propylene glycol chromatograms by means of those spot tests, enumerated earlier, which did not test for $\alpha$-ketols but have been found to react with groupings on the molecule which apply specifically here (32-39). In some instances there was overlapping on the chromatograms with $\alpha$-ketols of similar polarity, and complete separation, sufficiently satisfactory for complete identification, was not accomplished until after acetylation.

Seventeen-ketosteroids. The urines which had been extracted at $\mathrm{pH} 6.8$ after enzyme hydrolysis were next adjusted to $\mathrm{pH} 1$ with 50 per cent sulfuric acid and again continuously extracted with ether for 48 hours. These extracts were dried and washed in the same manner as those containing largely the $\alpha$-ketolic steroids. The total amounts of Zimmermann-reacting substances were then measured. Separation of the individual 17-ketosteroids was accomplished by paper chromatography utilizing the benzene/formamide, cyclohexane/formamide, and cyclohexane: hexane/formamide systems (25). The Zimmermann reaction, when used to spot the compounds on the paper, was performed with aqueous $\mathrm{KOH}$. For quantitation, alcoholic $\mathrm{KOH}$ (28) was used. The overflow from Fraction A of the $\alpha$-ketol procedure was chromatographed with cyclohexane: hexane/formamide, the spots located, identified and quantitated, and the results pooled with those of the pH 1.0 extract (Table II). Six compounds were present in sufficient quantity for ready separation, quantitation, and identification by comparing their mobilities and infrared absorption spectra with authentic compounds. In addition there were 5 compounds which were present in insufficient quantity to identify definitely.

\section{RESULTS}

Corticosteroids. The steroids isolated and identified prior to any treatment of the patient and during cortisone therapy are listed in Table I and 


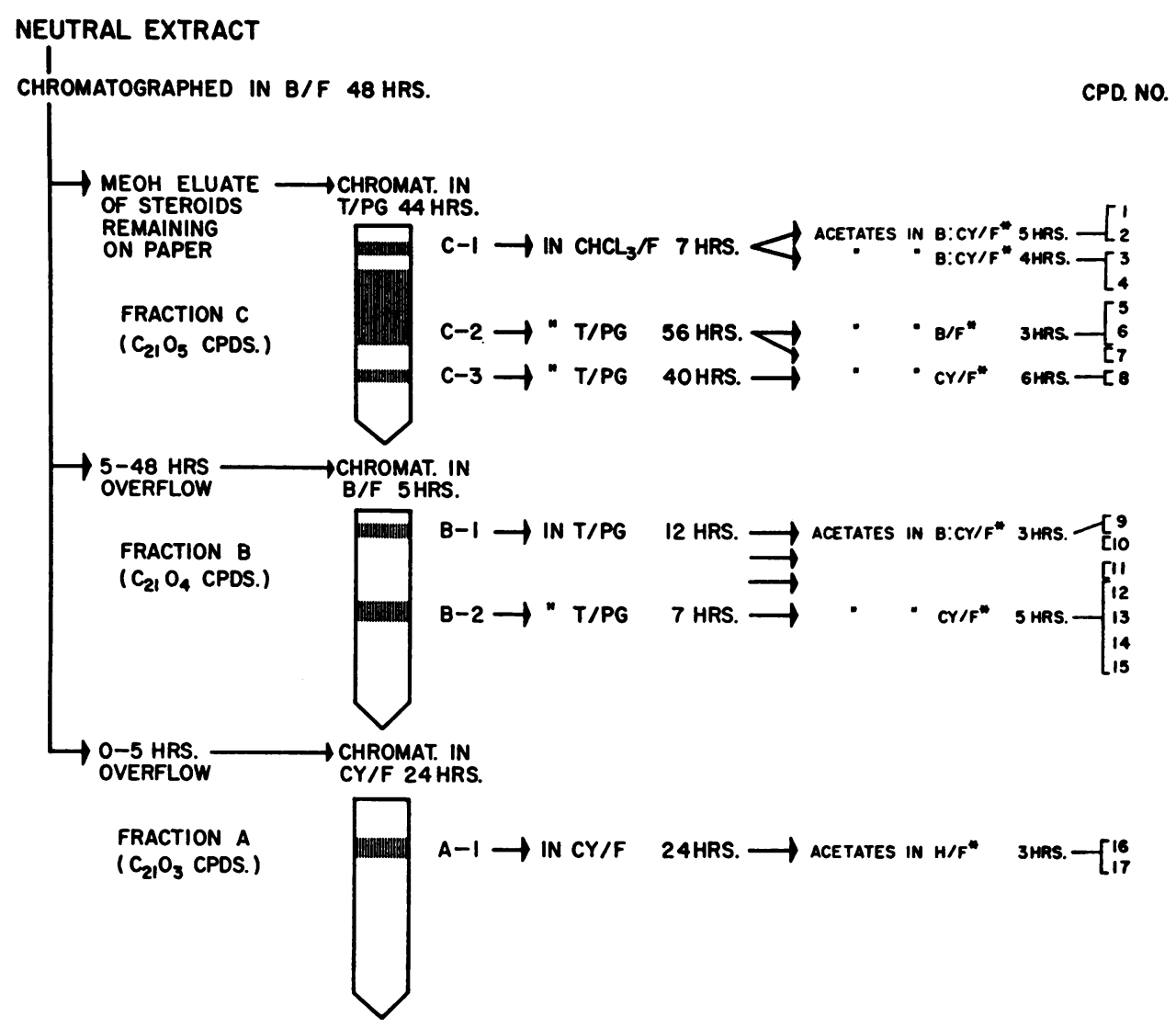

Fig. 1. Scheme of the fractionation By PAPER Chromatography. In each instance the overflow from the chromatograms was added to the subsequent, less polar material before this was chromatographed. This assured against loss of any steroids throughout.

Abbreviations: $\mathrm{B} / \mathrm{F}=$ benzene/formamide. $\mathrm{T} / \mathrm{PG}=$ toluene/propylene glycol. $\mathrm{CY} / \mathrm{F}=\mathrm{cy}-$ clohexane/formamide. $\quad \mathrm{CHCl}_{3} / \mathrm{F}=$ chloroform/formamide. $\mathrm{H} / \mathrm{F}=$ hexane/formamide. $B: C Y / F=$ equal volumes of benzene and cyclohexane/formamide. In the case of formamide, when an asterisk appears on the diagram, it denotes that undiluted solvent was used to impregnate the paper for the stationary phase; the absence of an asterisk indicates that the formamide was diluted with an equal part of methanol before impregnating the paper.

their properties summarized. The identity of a number of them could not be established. The patient excreted 18.6 to $27.7 \mathrm{mg}$ of $\alpha$-ketolic steroids per day prior to cortisone therapy. The $\alpha$-ketolic content of the urine pool used for chromatography was $21.0 \mathrm{mg}$ per day which was six times the amount excreted by normal children of comparable age (41).

\section{Identified ketolic steroids}

Tetrahydro $S$. The predominant $\alpha$-ketol isolated from the most polar fraction (Fraction $\mathrm{C}$ ), designated as Compound 6 in Table I and Figure 1 , accounted for 68 per cent of the total $\alpha$-ketolic steroids excreted per 24 hours. The free compound as well as its acetate had the same chromatographic mobilities as had authentic tetrahydro $\mathrm{S}$ and its acetate. The free compound and its acetate reacted with blue tetrazolium to give an intense blue color. When the compound was dissolved in methanol, no peak was found in the ultraviolet absorption spectrum. The sulfuric acid chromogen of both the free compound and its acetate gave an absorption peak at $314 \mathrm{~m} \mu$ and a plateau extending from 400 to $420 \mathrm{~m} \mu$. This pattern was identical to what we observed with known tetrahydro S (T.H.S.). An infrared absorption spectrum of the acetylated compound in carbon di- 
TABLE I

Quantities and some properties of the steroids isolated from the urine of D.G.*

\begin{tabular}{|c|c|c|c|c|c|c|c|c|}
\hline \multirow[b]{2}{*}{ Treatment } & \multirow[b]{2}{*}{ Fraction } & \multirow[b]{2}{*}{$\begin{array}{l}\text { Alpha } \\
\text { ketols }\end{array}$} & \multirow[b]{2}{*}{$\begin{array}{l}\text { Com- } \\
\text { pound } \\
\text { no. }\end{array}$} & \multicolumn{3}{|c|}{ Spot test reactions } & \multirow[b]{2}{*}{$\begin{array}{l}\text { U.V. absorption spectra max. } \\
\text { in conc. sulfuric acid }\end{array}$} & \multirow[b]{2}{*}{ Steroid } \\
\hline & & & & $\begin{array}{l}\text { Blue } \\
\text { tetra- } \\
\text { zolium }\end{array}$ & $\begin{array}{l}\text { 2,4-Dinitro- } \\
\text { phenyl- } \\
\text { hydrazine }\end{array}$ & $\begin{array}{c}\text { Periodate } \\
\text { oxidation } \\
+ \\
\text { Zimmer- } \\
\text { mann }\end{array}$ & & \\
\hline & & $m g / 24 h r$ & & & & & $m_{\mu}$ & \\
\hline \multirow[t]{19}{*}{ None } & Total & & & & & & & \\
\hline & $\begin{array}{l}\text { Neutral } \\
\mathrm{C}-1\end{array}$ & 21.2 & 1 & + & 0 & 0 & 260 (shoulder), 310, 410, & Unidentitied \\
\hline & & 0.8 & 2 & + & 0 & 0 & $\begin{array}{l}510 \text { (shoulder) } \\
260 \text { (shoulder), 325, 410, } \\
510 \text { (shoulder) }\end{array}$ & Tetrahydro F \\
\hline & & 0.5 & 3 & + & 0 & 0 & 315,410 & Unidentified \\
\hline & & 1.5 & 4 & + & 0 & 0 & $325-330,410$ & Tetrahydro E \\
\hline & $\mathrm{C}-2$ & & 5 & 0 & 0 & + & 315 & $\begin{array}{l}\text { Pregnane-3 } \alpha, 17 \alpha, \\
20 \xi, 21 \text {-tetrol }\end{array}$ \\
\hline & & 14.7 & 6 & + & 0 & 0 & $315,400-20$ (plateau) & Tetrahydro $\mathrm{S}$ \\
\hline & & & 7 & 0 & 0 & + & 310,410 (shoulder) & $\begin{array}{l}\text { Three } \alpha, 17 \alpha, 20 \alpha- \\
\text { trihydroxy preg- } \\
\text { nane-11-one }\end{array}$ \\
\hline & $\mathrm{C}-3$ & 0.2 & 8 & + & orange & 0 & $\begin{array}{l}268,315,440,500 \\
\quad \text { (shoulder) }\end{array}$ & Dihydro $\mathrm{S}$ \\
\hline & B-1 & 0.9 & 9 & + & 0 & 0 & $\begin{array}{l}315,440,500-520 \\
\quad \text { (shoulder) }\end{array}$ & Unidentified \\
\hline & & & 10 & 0 & 0 & + & $310,440,510$ (shoulder) & 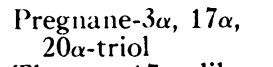 \\
\hline & & & 11 & 0 & yellow & 0 & 320 & $\begin{array}{l}\text { Three } \alpha, 17 \alpha, \text { dihy- } \\
\text { droxy-pregnane- } \\
\text { 20-one }\end{array}$ \\
\hline & B-2 & & 12 & 0 & orange & 0 & $280,330,420$ & Unidentified \\
\hline & & 0.1 & 13 & + & 0 & 0 & 270,320 & Unidentified \\
\hline & & 0.2 & $\begin{array}{l}14 \\
15\end{array}$ & $\begin{array}{l}0 \\
+\end{array}$ & $\begin{array}{l}\text { yellow } \\
0\end{array}$ & 0 & $265,295,310$ & Tnidentified \\
\hline & A-pig. & 0.2 & & 0 & $\begin{array}{l}0 \\
0\end{array}$ & $\begin{array}{l}0 \\
0\end{array}$ & $305-10,375,400$ & $\begin{array}{l}\text { Cnidentified } \\
\text { Pigments }\end{array}$ \\
\hline & $A-1$ & 0.6 & 16 & + & yellow & 0 & $285-290,360-70,435$ & Dihydro DOC \\
\hline & & 1.0 & 17 & + & 0 & 0 & $310,380-410$ (plateau) & Tetrahydro DOC \\
\hline & $\begin{array}{l}\text { A-over- } \\
\text { flow }\end{array}$ & 0.5 & & trace & 0 & 0 & & $\begin{array}{l}\text { 17-Ketosteroids and } \\
\text { pigments }\end{array}$ \\
\hline \multirow[t]{10}{*}{ Cortisone } & $\begin{array}{l}\text { Total } \\
\text { Neutral }\end{array}$ & 12.4 & & & & & & \\
\hline & $\mathrm{C}-1$ & 0.3 & 1 & + & 0 & 0 & $\begin{array}{l}260 \text { (shoulder), } 320,410 \\
500 \text { (shoulder) }\end{array}$ & Enidentified \\
\hline & & 2.0 & 2 & + & 0 & 0 & $\begin{array}{l}260 \text { (shoulder), } 318,410 \text {, } \\
510 \text { (shoulder) }\end{array}$ & Tetrahydro F \\
\hline & & $\begin{array}{l}0.5 \\
5.0\end{array}$ & 3 & + & 0 & 0 & 320,410 & Unidentified \\
\hline & $\mathrm{C}-2$ & $\begin{array}{l}5.0 \\
0.7\end{array}$ & $\begin{array}{l}4 \\
5\end{array}$ & $\begin{array}{l}+ \\
+\end{array}$ & $\begin{array}{c}0 \\
\text { yellow }\end{array}$ & $\begin{array}{l}0 \\
+\end{array}$ & 325,410 & Tetrahydro E \\
\hline & $B-1$ & 0.2 & & & & $T$ & (shoulder) & \\
\hline & & 0.6 & 7 & + & $\begin{array}{l}0 \\
0\end{array}$ & $\begin{array}{l}0 \\
0\end{array}$ & $\begin{array}{l}305-10,420 \\
305\end{array}$ & $\begin{array}{l}\text { letrahydro B } \\
\text { Unidentified }\end{array}$ \\
\hline & & 0.4 & 8 & + & yellow & 0 & $255,305,375,420-30$ & Unidentified \\
\hline & $A-1$ & 0.4 & 9 & + & yellow & 0 & $\begin{array}{l}280,355-65,420,510 \\
\text { (shoulder) }\end{array}$ & Unidentified \\
\hline & A-over- & 0.6 & & 0 & 0 & 0 & & $\begin{array}{l}\text { 17-Ketosteroids and } \\
\text { pigments }\end{array}$ \\
\hline
\end{tabular}

* None of the compounds when dissolved in methanol gave an absorption peak in ultraviolet light. All compounds failed to produce fluorescence when treated with sodium hydroxide. None of the compounds gave a blue color when treated with iodine solution (22).

sulfide was likewise identical to that of authentic T.H.S.. A smaller amount $(3.5 \mathrm{mg})$ of T.H.S. was identified in the urine extract obtained after hot acid hydrolysis. It was quantitated and the amount is included in Table I. Insignificant amounts of several of the other $\alpha$-ketols in Table I were spotted in this extract.

Tetrahydrocortisol. Compounds 1 and 2 were not separated in the free state with the toluene/ propylene glycol and chloroform/formamide sys- 
tems. As acetates they were separated from one another when chromatographed in the benzene: cyclohexane/formamide system. The chromatographic mobility of the acetate of Compound 2 was identical to that of authentic tetrahydrocortisol diacetate in a mixed chromatogram. An absorption spectrum given by the sulfuric acid chromogen and the infrared absorption spectrum of the acetylated compound in a potassium bromide disc was identical with that of authentic tetrahydrocortisol.

Tetrahydrocortisone. Compound 4 exhibited chromatographic mobility identical to that of authentic tetrahydrocortisone in the free state and as acetate. Its reaction with blue tetrazolium, its nonreactivity with the other spotting reagents, and its failure to absorb ultraviolet light characterized it as a saturated $\alpha$-ketol. The sulfuric acid chromogen and the infrared absorption spectra were identical to those of known tetrahydrocortisone diacetate.

Dihydro $S$. Compound 8 behaved like dihydro S. In the free form and as acetate it exhibited polarity similar to Compound $\mathrm{E}$ and its acetate. However, it gave a color, when treated on paper with 2,4 dinitrophenylhydrazine, which suggested the presence of a nonconjugated ketone group in Ring A. The sulfuric acid chromogen pattern was identical to that of authentic dihydro S.

Dihydrodesoxycorticosterone and tetrahydrodesoxycorticosterone. The two $\alpha$-ketols found in Fraction A (Compounds 16 and 17) were of more than ordinary interest. Alpha-ketols have not been found in the urine of normal persons in this fraction $(25,41)$. In the free form they moved as a single wide band which was slightly more polar than desoxycorticosterone (cyclohexane/formamide and a number of other systems). The more polar of the two acetates (no. 16) was compared with allo-dihydrodesoxycorticosterone acetate since dihydrodesoxycorticosterone acetate was not available to us. The movements of the unknown and reference compounds were identical in hexane/ formamide as well as in cyclohexane/formamide. The sulfuric acid chromogen was identical to that of dihydrodesoxycorticosterone (42).

The less polar of the two acetates (no. 17) exhibited chromatographic behavior like the acetate of tetrahydrodesoxycorticosterone in hexane/ formamide, cyclohexane/formamide, and cyclo-
TABLE II

17-Ketosteroids isolated from the urine of patient D.G.

\begin{tabular}{|c|c|c|c|}
\hline & $\begin{array}{c}\text { Ex- } \\
\text { tracted } \\
\text { at } \\
\text { pH } 1.0\end{array}$ & $\begin{array}{c}\text { Ex- } \\
\text { tracted } \\
\text { at } \\
\text { pH } 6.8\end{array}$ & Total \\
\hline $\begin{array}{l}\text { Androsterone } \\
\text { Etiocholanolone } \\
\text { 11-Keto androsterone } \\
11 \text { Keto etiocholanolone } \\
11 \text { Beta hydroxyandrosterone } \\
\text { 11 Beta hydroxyetiocholanolone } \\
\text { Unidentified }\end{array}$ & $\begin{array}{l}m g / 24 h r \\
2.8 \\
1.3 \\
1.8 \\
0.2 \\
0.3 \\
0.2 \\
0.8\end{array}$ & $\begin{array}{c}m g / 24 h r \\
2.3 \\
2.6\end{array}$ & $\begin{array}{c}m g / 2+h r \\
5.1 \\
3.9 \\
1.8 \\
0.2 \\
0.3 \\
0.2 \\
0.8\end{array}$ \\
\hline & & & 12.3 \\
\hline
\end{tabular}

hexane: benzene/formamide systems. The sulfuric acid chromogen and the infrared absorption spectra were identical to those given by authentic tetrahydrodesoxycorticosterone.

Alpha-ketols not completely characterized. Five additional $\alpha$-ketolic compounds were separated in varying amounts (Compounds 1, 3, 9, 13, 15). All seemed to be saturated in Ring A. Many of the characteristics of Compounds 1 and 3 suggested that they were probably "allo" isomers of tetrahydro $F$ and tetrahydro $E$, respectively (43, 44). The polarity of the others ranged from slightly less than that of cortisone to slightly less than that of 11-dehydrocorticosterone. Neither their chromatographic behavior as free steroids, or as acetates, their sulfuric acid chromogen spectra, nor the various spot tests or derivatives aided in their identification. Compound 9 may possibly have been tetrahydro A contaminated with another steroid. The sulfuric acid chromogen curve did not resemble the two identified steroids found next to it.

Non- $\alpha$-ketolic C-21 steroids. Two glycols were found in Fraction C-2 of the toluene/propylene glycol chromatogram. The total amount per 24 hours was $1.6 \mathrm{mg}$.

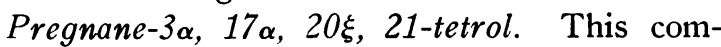
pound (no. 5 in Figure 1 and Table I) was found between tetrahydrocortisone and tetrahydro $\mathrm{S}$; it overlapped with the latter before acetylation. When compared with known samples of Compounds $F$ and $E$ its chromatographic mobility was found to be similar to Compound F. It did not react with blue tetrazolium and gave a positive Zimmermann spot after periodate oxidation. With phosphomolybdic acid it gave a blue color. 
It did not become fluorescent when treated with sodium hydroxide and no color was produced with dinitrophenylhydrazine. Its sulfuric acid chromogen had a peak at 314. An infrared absorption spectrum had peaks which were identical to those described by Eberlein and Bongiovanni (9) for this compound.

When the compound was oxidized a 17-ketosteroid was produced which, when chromatographed in the cyclohexane/formamide system, had mobility identical to etiocholanolone.

Three $\alpha, 17 \alpha, 20 \alpha$-trihydroxy-pregnane-11-one. This compound (no. 7 in Figure 1 and Table I) was less polar than tetrahydro $\mathrm{S}$ when found on the toluene/propylene glycol chromatogram. It was also less polar than Compound $\mathrm{E}$ when compared with a known sample of this compound. It was spotted by treatment with 70 per cent phosphoric acid, which produced a fluorescence (37, 38). It did not react with blue tetrazolium but gave a positive Zimmermann reaction after oxidation with periodate. It gave a strong blue color with phosphomolybdic acid (36), did not fluoresce when treated with sodium hydroxide, and 2,4-dinitrophenylhydrazine produced no color. A sulfuric acid chromogen spectrum had a peak at 310 and a shoulder at 410 . When the acetates of this compound and of pregnane- $3 \alpha, 17 \alpha, 20,21$ tetrol were chromatographed their polarity was in the reverse order of the free compounds. This suggests that the unknown compound (no. 7) had fewer hydroxyl groups available for acetylation than the identified glycol-3 $\alpha, 17 \alpha, 20 \xi, 21$-tetrol.

After oxidation with periodate or chromic acid the unknown compound yielded a 17-ketosteroid which, when chromatographed with cyclohexane/ formamide, moved identically to 11-keto-etiocholanolone. The quantity was insufficient for further tests. All the above information, especially the comparison with the findings on $3 \alpha, 17 \alpha, 20,21$ tetrol, suggests that this glycol did not have an oxygen function at the 21-carbon but had one on carbon-11. The most likely compound to fit all the above findings is $3 \alpha, 17 \alpha, 20 \alpha$-trihydroxy-pregnane-11-one.

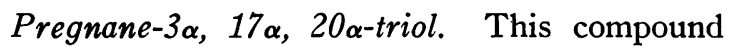
(no. 10 in Table I) was found in the upper part of Fraction B, slightly less polar than the blue tetrazolium zone designated B-1 in Figure 1. It was less polar than tetrahydro $\mathrm{B}$ and tetrahydro
A, both in the free form and as acetates. The acetate was also less polar than desoxycorticosterone acetate. The free compound, when located on the paper chromatograms with phosphoric acid, gave a violet color and pink fluorescence $(37,38)$. When treated with trichloracetic acid (39) it gave a blue color in daylight and blue fluorescence. It did not react with blue tertazolium and all reactions for $\Delta 4$, 3-keto groups were negative. After periodate oxidation, according to the method of Romanoff and Hunt (34), it gave a weak Zimmermann reaction. With phosphomolybdic acid it gave a blue color (36). In sulfuric acid it formed a pale orange color (9) and its sulfuric acid chromogen absorption spectrum had a major peak at 440 , a minor peak at 310 and a shoulder at 510 .

The amount, in addition to having been done on an aliquot of urine as mentioned in the case report, was again quantitated by eluting the compound off the paper and applying the formula of Allen to the absorption spectrum obtained with a sulfuric acid chromogen. In this manner $4.8 \mathrm{mg}$ per 24 hours was calculated to be present.

Three $\alpha, 17 \alpha$-dihydroxy-pregnane-20-one. This compound (no. 11 in Table I) was detected on the paper by its reaction with 2,4-dinitrophenylhydrazine, thus characterizing a ketone group in the molecule. Its polarity was somewhat less than dihydro $S$ and pregnanetriol. It did not reduce blue tetrazolium and did not have an ultraviolet light absorption peak when dissolved in methanol. After chromatography of the acetate its sulfuric acid chromogen absorption spectrum consisted of a peak at $320 \mathrm{~m} \mu$. This was identical to the spectrum yielded by authentic $3 \alpha, 17 \alpha$-dihydroxy-pregnane20-one (42). An infrared absorption spectrum also coincided with that given by this compound. While most of the compound was sharply localized in this region of the chromatogram, traces were also distributed to some extent throughout Fractions $\mathrm{B}$ and $\mathrm{A}$ in the preliminary fractionation and necessitated rechromatography of certain of the other steroids in order to clean them up satisfactorily for identification. Similar difficulties were encountered by Fukushima and Gallagher (17) when a urine extract contained large amounts of pregnane-3 $\alpha, 17 \alpha, 20 \alpha$-triol. From the aliquot used $8.4 \mathrm{mg}$ of the compound in crystalline form was isolated, and this accounted for an excretion of slightly more than $25 \mathrm{mg}$ daily. 
Pregnane-3 $\alpha, 20 \alpha-d i o l$ was found in Fraction A by spotting with phosphomolybdic and silicotungstic acids. It was cleaned up by chromatography using a toluene : methyl cyclohexane/propylene glycol system and identified by its sulfuric acid and infrared absorption spectra.

Two other nonketolic substances were isolated from Fraction B (Compounds 11 and 13). These substances, like Compound 9, reacted with 2,4dinitrophenylhydrazine. From the chromatographic mobility of Compound 13 before and after acetylation we inferred formation of a diacetate. Further identification was not possible. A number of lesser spots were found during treatment with phosphoric acid and phosphomolybdic acid, but their nature was not determined.

Seventeen-ketosteroids. The three 24 hour urine specimens contained an average of $17 \mathrm{mg}$ of 17-ketosteroid after hydrolysis with hot hydrochloric acid. In order to avoid the confusion caused by artifacts produced by the hot acid (45) the chromatography and identification were performed on extracts prepared as described in "Methods." This, we believe, assured us that the identified metabolites were excreted as such by the patient.

In Table II are recorded the six $\mathrm{C}_{19}$ compounds which were isolated, quantitated and identified by their infrared absorption spectra. Five additional compounds were found in minute amounts, too small to identify. These are all included in the table under "unidentified." The sum of the 17ketosteroids thus found was $12.2 \mathrm{mg}$. According to the work of Brooks (29) this is a reasonable amount when compared with the quantity found after hot acid hydrolysis.

Cortisone treatment period. The excretion of 17-ketosteroids reverted to normal levels while the patient was receiving cortisone. There was also a decrease in the daily excretion of $\alpha$-ketols and there was a marked change in their pattern. The predominant $\alpha$-ketols were tetrahydrocortisol and tetrahydrocortisone which accounted for approximately 57 per cent of the total $\alpha$-ketols excreted. A small amount of tetrahydro B was also found. It is possible that its presence in small amounts during the pretreatment period was missed because of the large quantities of abnormal steroids located in the same regions of the chromatogram (Fraction B-1). It could also have been due to contamination of the administered cortisone by Compounds A or B. The metabolites of Compound $\mathrm{S}$ and desoxycorticosterone noted prior to cortisone therapy were not found. Some of the unidentified compounds exhibited properties identical to some of the unidentified compounds found during the pretreatment period. This phenomenon may have been due to the cortisone dosage being insufficient to suppress completely $\mathrm{ACTH}$ production.

\section{DISCUSSION}

Adrenal gland perfusions and adrenal vein blood analyses indicate that cortisol and cortisone are the major products of adrenocortical secretion in man. The synthesis of Compound $F$ via pregnenolone (46) is dependent upon hydroxylating enzymes which introduce oxygen function at C-17, $\mathrm{C}-21$ and C-11 positions, usually in sequential fashion in the order named, according to Hechter and Pincus (47).

Patients exhibiting congenital adrenal hyperplasia with virilization are considered to have a metabolic defect which does not allow synthesis of cortisol at a normal rate. All of the clinical and laboratory findings which have been reported are in keeping with this hypothesis. In the plasma, low levels of 17-hydroxycorticoids and high levels of ACTH have been reported (11). Administration of adrenocorticotropin usually has not augmented appreciably the levels of corticoids in the serum or urine $(10-13,48,49)$. Exceptions to this have been reported $(16,50)$. These variations of response from case to case probably depend upon whether or not the adrenals are responding maximally to intrinsic ACTH before administration of the extrinsic material. This in turn may depend upon differences in the quantitative extent of the defect. In the cases described prior to 1955 the known metabolites of cortisol were not found $(7,8,11)$. Since then, however, both tetrahydrocortisone and tetrahydrocortisol have been isolated from the urines of untreated patients with adrenogenital syndrome (15-18). The explanation proposed by Bongiovanni and Eberlein, and which has been supported by others (18), namely, that the fault is relative and not absolute, explains these findings in a highly satisfactory manner. Indeed, the ability to synthesize, with sufficient stimulation by $\mathrm{ACTH}$, adequate 


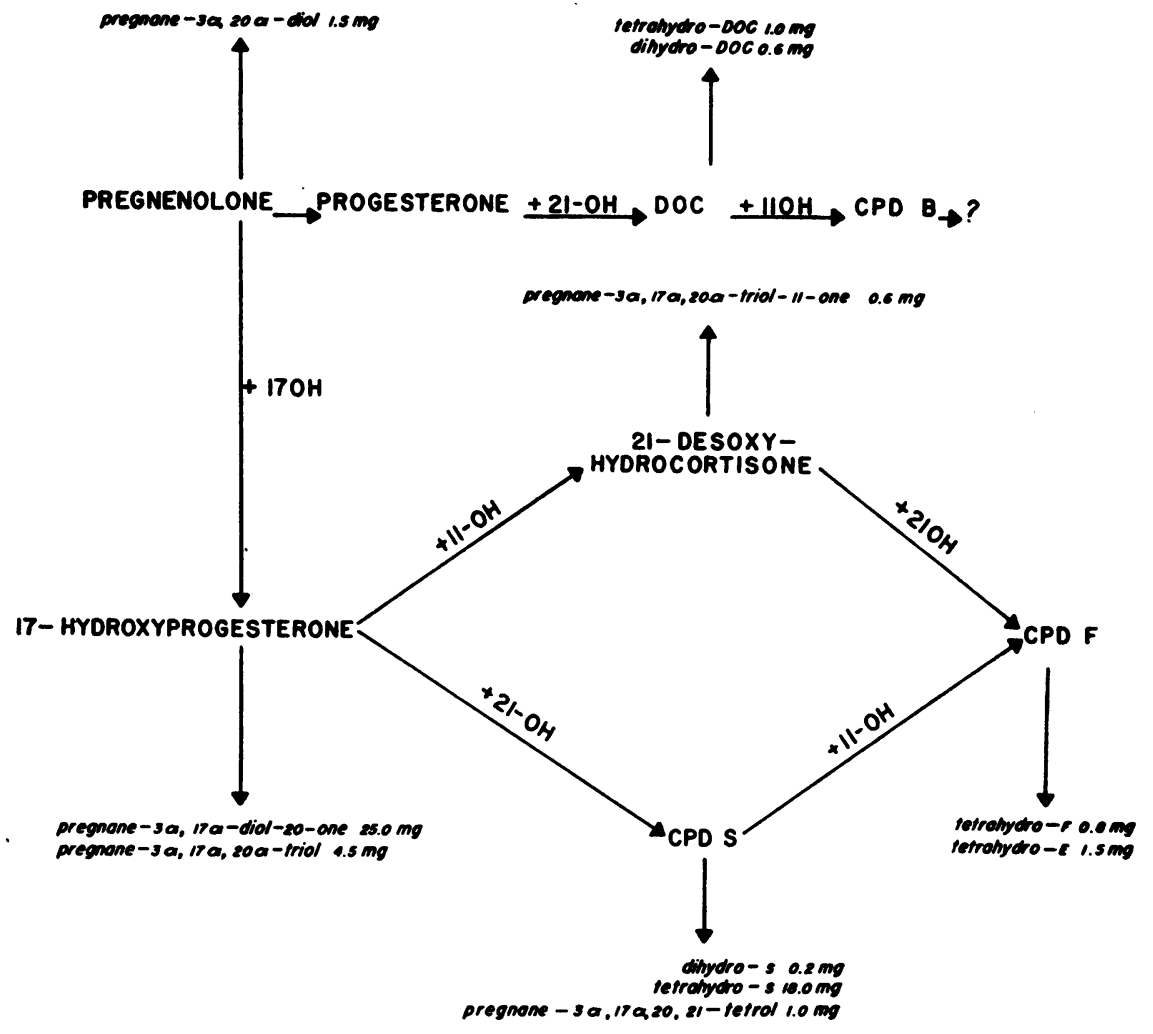

Fig. 2. A SCHEME to EXPLAIN THE ALPHA-KETOLIC METABOlites FOUND IN THE URINE OF A NORMOTENSIVE BOY WITH ADRENOGENITAL SYNDROME. The steroid metabolites which were separated and measured are printed in small slanted type. The probable precursors and their interrelations are printed in capitals. Impaired 11- and 21hydroxylase activities are postulated.

amounts of cortisol probably explains why most of these patients remain in good general health.

The urinary steroid pattern in the case described here had certain similarities to that found in the case with hypertension reported by Eberlein and Bongiovanni (9); however, there were marked differences in both kind and amount of metabolites isolated. In Figure 2 we have indicated the most probable precursors of the various $\mathrm{C}_{21}$ metabolites found in the urine of our patient. Implications as to the abnormalities in synthesis are derived from the amounts and types of these metabolites. At the same time the presence of the 17-ketosteroids listed in Table II should be taken into consideration.

The levels of excretion of metabolites of Compound $\mathrm{S}$ and of desoxycorticosterone in the two patients were of roughly the same order. In ours we found slightly more tetrahydro $S$ but in the case of Eberlein and Bongiovanni (9) there was more $3 \alpha, 17 \alpha, 20$ ?, 21-tetrol. In both cases the excretion levels of these compounds were of such magnitude that they very definitely implied failure of $11 \beta$-hydroxylation (47). The inference that these amounts of metabolites imply formation by the adrenals of the same amounts of the parent compounds is perhaps plausible, but not certain.

In normal individuals the above metabolites are not found to any great extent. Touchstone, Bulaschenko, Richardson and Dohan (51) thought that a group of normal men and women excreted about $20 \mu \mathrm{g}$ of tetrahydro $\mathrm{S}$ daily. It was not always present, however, even in such small amounts, in normal persons, pregnant women or diabetics. Less than $10 \mu \mathrm{g}$ per day has been found in the urine of a group of normal children studied in our laboratory. Romanoff and Wolf found none in a series of normal adults or patients with schizophrenia (52).

It is interesting that Hechter and colleagues 
predicted some years ago (53) that if a clinical condition should arise in which there is an insufficiency of 11-hydroxylating enzyme, such persons would execrete metabolites of Compound S. Several such conditions, in addition to the subject of this paper, can be cited. When Compound $S$ was administered to patients with adrenal insufficiency, tetrahydro $S$ was found in the urine in considerable quantities (54). In some patients with adrenal cortical tumors considerable quantities of tetrahydro $S$ have been found in the urine (54-56), probably because the production of Compound $S$ was so great that the capacity of the 11hydroxylating mechanism was exceeded, or the subjects had defects in the 11-hydroxylating mechanism.

The most striking difference between the case reported here and that of Eberlein and Bongiovanni (9) was the unquestionable evidence for the presence in our patient of $11 \beta$-hydroxylating enzyme. This conclusion is based on the isolation of tetrahydro $\mathrm{F}$, tetrahydro $\mathrm{E}$, and the four 11oxygenated 17 -ketosteroids recorded in Table II. The overall pattern of the urinary metabolites as well as clinical evidence indicate that the capacity on the part of the adrenals to perform this function was reduced.

The possibility exists that the degree or severity of the block is of importance and that the amount of DOC synthesized and its effect on blood pressure would depend on this. The finding of similar quantities of metabolites of DOC may be against this but not definitely so. In addition, one would expect that the amount of 11-oxygenated metabolites excreted would give an indication of the degree of the defect. No conclusions in reference to this point can be drawn from published cases. To our knowledge there have been reported five cases of adrenogenital syndrome in whom the major metabolite found in the urine was tetrahydro $\mathrm{S}(9,19,20,57)$. Metabolites of DOC were reported in only the case of Eberlein and Bongiovanni (9). One can assume that they were present in some of the other cases if not in all. In all cases except that of Eberlein and Bongiovanni evidence of some degree of $11 \beta$-hydroxylation was found in the form of either 11oxygenated $C_{21}$ or $C_{19}$ steroids or both. There was no correlation between the presence or absence of these metalsolites and hypertension. There was no correlation of blood pressure with age or sex.

Of equally great interest and perhaps importance was the finding in our case of greater quantities of metabolites of 17-hydroxyprogesterone $(25 \mathrm{mg}$ of $3 \alpha, 17 \alpha$-dihydroxy-pregnane-20-one. and $4.5 \mathrm{mg}$ of pregnane-3 $\alpha, 17 \alpha, 20 \alpha$-triol) than metabolites of Compound $\mathrm{S}$, as indicated in Figure 2. The amounts were verified by repeated analyses on several aliquots of the three 24 hour specimens. Three $\alpha, 17 \alpha, 20$-trihydroxypregnane-11-one, a metabolite of 21-desoxycortisone, was almost certainly also found. All these metabolites have been found in cases of adrenogenital syndrome with deficiency of C-21-hydroxylation (16). In the light of these findings a relative insufficiency of 21 hydroxylating function is strongly suggested in our case. It is plausible, therefore, that this boy had partial insufficiency of both 11- and 21-hydroxylating enzymes.

It is of slight interest that the 20-keto metabolites of 17-hydroxyprogesterone were more abundant than the 20-hydroxy metabolites, as is usually the case (17). This could imply some difference of metabolism from the usual in either adrenals or liver. The proportions are the same, of course, as in the case of metabolites of hydrocortisone under normal conditions.

Hypertension has never been described in patients with adrenogenital syndrome who have defects in 21-hydroxylation. The hypertension, therefore, appears to occur only in some of those patients with defects in $11 \beta$-hydroxylation. Our studies, however, as well as several other reports, show that the occurrence of normal blood pressure in this syndrome does not rule out a defect in 11-hydroxylation or establish that the major defect is at the 21 position.

Some additional remarks concerning observations which have been made on some of the adrenal cortical steroids that are made consequent to the defect of $\mathrm{C}-11$ are in order. In no studies with Compound $\mathrm{S}$ was there evidence that hypertension could be attributed to it. Bergenstal, Huggins and Dao (58) gave 25 to $50 \mathrm{mg}$ of Compound $\mathrm{S}$ intramuscularly to adrenalectomized patients. It was followed only by minimal salt retention and no carbohydrate effect. The patients were weak and anorectic and exhibited fall in their blood pressure. Other clinical studies indicated that 
quantities as large as $200 \mathrm{mg}$ per day had to be given to induce detectable changes in sodium chloride balance (59). Still other investigators $(60,61)$, studying the metabolism of Compound S, have given this orally and intramuscularly in doses up to $1 \mathrm{~g}$ per day without noting alteration in blood pressure.

While there is no good evidence for etiologic relationship between desoxycorticosterone per se and most clinical hypertensive states, there is evidence which indicates that there may be some circumstances in which desoxycorticosterone can cause hypertension. Some authors think that when this occurs it is a consequence of the sodium retention caused by the hormone; others have presented data which contradict this.

In almost all studies involving the administration of desoxycorticosterone to animals or man there have been wide variations in the degree of response by individuals or groups of individuals. This was noted in the earliest reports concerning the use of this hormone in the treatment of Addison's disease (62-64). The patients varied greatly in the amount of hormone esters required to alleviate the manifestation of adrenal insufficiency. With the same doses wide variations were noted in sodium chloride and water retention, in body weight changes, edema formation, and effects on blood pressure.

When desoxycorticosterone was given to normotensive, spontaneously hypertensive, and Goldblatt-hypertensive dogs, 9 out of 12 dogs developed hypertension; 3 did not (65). Perera and Blood (66) administered desoxycorticosterone to 10 normotensive and 15 hypertensive individuals while they were under strict metabolic control. The normotensive individuals developed no change of basal blood pressure, while in the hypertensives both systolic and diastolic pressures increased. The authors were of the opinion that changes in body weight and salt balance were the same in both groups; therefore, they did not accept electrolyte retention as being the crucial factor responsible for the increase in blood pressure.

Some of the work by Davies and Clark (67) suggests that increase of blood pressure after administration of desoxycorticosterone may not result from a direct effect of the steroid on blood vessels, but the hormone may condition them for an increased response to pressor substances. They administered $5 \mathrm{mg}$ of desoxycorticosterone acetate twice daily to 15 individuals for 15 days. The response to injection of epinephrine and norepinephrine was measured repeatedly before and after treatment with desoxycorticosterone acetate. While the resting pressures were not significantly altered, there was invariably an increase of pressor response after pretreatment with desoxycorticosterone acetate.

Recently Liddle and associates (68) and Jenkins and associates (69) gave an $11 \beta$-hydroxylase inhibitor (2-methyl-1,2-bis[3-pyridyl]-1-propanone) to normal nonstressed persons. Compound $\mathrm{S}$ and other 11-desoxycorticosteroids were isolated from the serum and large quantities of their metabolites were isolated from the urine of these subjects. The blood pressure was not affected; it is entirely possible that it would have been with longer administration or larger doses. Experience with administration of desoxycorticosterone to patients with Addison's disease certainly showed that, when larger doses of this drug were given, it took several months in some patients for the blood pressure to reach hypertensive levels.

\section{SUMMARY}

The urinary steroid pattern of an untreated normotensive 5.5 year old boy with congential virilizing adrenal hyperplasia has been studied.

Abnormally large amounts of metabolites of Compound $\mathrm{S}$ and of desoxycorticosterone were found. This indicates that hydroxylation at C-11 of the steroid nucleus was impaired.

The patient also excreted normal or near normal amounts of tetrahydro $F$, tetrahydro $E$, and other metabolites possessing an oxygen grouping at C-11. This is interpreted to indicate that the patient was capable of hydroxylation at this position when the adrenals were subjected to excessive stimulation by endogenous ACTH.

Large amounts of metabolites of 17-hydroxyprogesterone were also found. This was interpreted to indicate a relative insufficiency of $\mathrm{C}-21$ hydroxylation when this system was working under a load.

When hypertension accompanies the adrenogenital syndrome it probably indicates a defect in hydroxylation at $\mathrm{C}-11$ of the steroid nucleus and resulting excessive manufacture of DOC. A nor- 
mal blood pressure does not rule out the existence of this defect. The factors which determine the difference in blood pressure response are not known.

\section{ACKNOWLEDGMENTS}

The authors are grateful to Dr. Gilbert Forbes of the Department of Pediatrics of Strong Memorial Hospital for allowing them to study the patient. They are indebted to Drs. T. F. Gallagher and G. Roberts of the Sloan-Kettering Institute and Drs. A. Sandberg and R. Slaunwhite of the Roswell Park Memorial Institute for infrared spectra. Tetrahydrodesoxycorticosterone was kindly supplied by Dr. A. M. Bongiovanni.

\section{REFERENCES}

1. Wilkins, L. The diagnosis of the adrenogenital syndrome and its treatment with cortisone. J. Pediat. 1952, 41, 860.

2. Darrow, D. C. Congenital adrenal cortical insuffciency with virilism; case report. Yale J. Biol. Med. 1944, 16, 579.

3. Barnett, H. L., and McNamara, H. Electrolyte balance in a male infant with adrenocortical insufficiency and virilism. The effect of desoxycorticosterone acetate and salt therapy with special reference to potassium. J. clin. Invest. 1949, 28, 1498.

4. White, F. P., and Sutton, L. E. Adrenogenital syndrome with associated episodes of hypoglycemia. J. clin. Endocr. 1951, 11, 1395.

5. Shepard, T. H., II, and Clausen, S. W. Case of adrenogenital syndrome with hypertension treated with cortisone. Pediatrics 1951, 8, 805.

6. Williams, L., Crigler, J. F., Jr., Silverman, S. H., Gardner, L. I., and Migeon, C. J. Further studies on the treatment of congenital adrenal hyperplasia with cortisone. III. The control of hypertension with cortisone, with a discussion of variations in the type of congenital adrenal hyperplasia and report of a case with probable defect of carbohydrateregulating hormones. J. clin. Endocr. 1952, 12, 1015.

7. Eberlein, W. R., and Bongiovanni, A. M. Congenital adrenal hyperplasia with hypertension; unusual steroid pattern in blood and urine. J. clin. Endocr. 1955, 15, 1531.

8. Bongiovanni, A. M., and Eberlein, W. R. Clinical and metabolic variations in the adrenogenital syndrome. Pediatrics 1955, 16, 628.

9. Eberlein, W. R., and Bongiovanni, A. M. Plasma and urinary corticosteroids in the hypertensive form of congenital adrenal hyperplasia. J. biol. Chem. 1956, 223, 85.

10. Jailer, J. W. Virilism. Bull. N. Y. Acad. Med. 1953, 29, 377.

11. Kelley, V. C., Ely, R. S., and Raile, R. B. Hormone patterns in patients with congenital adrenal hyperplasia. Pediatrics 1953, 12, 541.
12. Lewis, R. A., and Wilkins, L. The effect of adrenocorticotropic hormone in congenital adrenal hyperplasia with virilism and in Cushing's syndrome treated with methyl testosterone. J. clin. Invest. 1949, 28, 394.

13. Bartter, F. C., Albright, F., Forbes, A. P., Leaf, A., Dempsey, E., and Carroll, E. The effects of adrenocorticotropic hormone and cortisone in the adrenogenital syndrome associated with congenital adrenal hyperplasia: An attempt to explain and correct its disordered hormonal pattern. J. clin. Invest. 1951, 30, 237.

14. Dorfman, R. I. The adrenogenital syndrome in Adrenal Function in Infants and Children, $L$. Gardner, Ed. New York, Grune and Stratton, 1956 , p. 90.

15. Eberlein, W. R., and Bongiovanni, A. M. Partial characterization of urinary adrenocortical steroids in adrenal hyperplasia. J. clin. Invest. 1955, 34, 1337.

16. Gandy, H. M. Partial characterization of $\mathrm{C}_{m}$ steroids in the urines of children with the adrenogenital syndrome (abstract). J. clin. Endocr. 1956, 16, 948.

17. Fukushima, D. K., and Gallagher, T. F. Steroid isolation studies in congenital adrenal hyperplasia. J. biol. Chem. 1958, 229, 85.

18. Bongiovanni, A. M., and Eberlein, W. R. Defective steroidal biogenesis in congenital adrenal hyperplasia. Pediatrics 1958, 21, 661.

19. Dyrenfurth, I., Sybulski, S., Notchev, V., Beck, J. C., and Venning, E. H. Urinary corticosteroid excretion patterns in patients with adrenocortical dysfunction. J. clin. Endocr. 1958, 18, 391.

20. Birke, G., Diczfalusy, E., Plantin, L. O., Robbe, H., and Westman, A. Familial congenital hyperplasia of the adrenal cortex. Acta Endocr. (Kbh.) 1958, 29,55 .

21. Wilkins, L. The Diagnosis and Treatment of Endocrine Disorders in Childhood and Adolescence, 2nd ed. Springfield, Charles C Thomas, 1957, p. 332.

22. Jailer, J. W., Gold, J. J., Vande Wiele, R., and Lieberman, S. 17 $\alpha$-Hydroxyprogesterone and 21desoxyhydrocortisone; their metabolism and possible role in congential adrenal virilism. J. clin. Invest. 1955, 34, 1639.

23. Izzo, A. J., Keutmann, E. H., and Burton, R. B. Special considerations in the use of blue tetrazolium for the measurement of alpha-ketols in mixtures with other steroids. J. clin. Endocr. 1957, 17, 889.

24. Bongiovanni, A. M. The detection of pregnandiol and pregnantriol in the urine of patients with adrenal hyperplasia, suppression with cortisone. A preliminary report. Johns Hopk. Hosp. Bull. 1953, 92, 244.

25. Burton, R. B., Zaffaroni, A., and Keutmann, E. H. Corticosteroids in urine of normal persons determined by paper chromatography. J. biol. Chem. 1951, 193, 769. 
26. Wilson, H., and Fairbanks, R. A micro-method for the detection and assay of steroid $\mathrm{C}_{21}-17$-hydroxyalpha-glycols. Arch. Biochem. 1955, 54, 457.

27. Talbot, N. B., Berman, R. W., and MacLachlan, E. A. Elimination of errors in colorimetric assay of neutral urinary 17 -ketosteroids by means of a color correction equation. J. biol. Chem. 1942, 143, 211.

28. Wilson, H., and Carter, P. Stabilization of the alcoholic potassium hydroxide in colorimetric 17 ketosteroid determinations. Endocrinology 1947, $41,417$.

29. Brooks, R. V. A method for the quantitative fractionation of urinary 17-oxosteroids with some observations on steroid excretion during administration of ACTH and in the adrenogenital syndrome. Biochem. J. 1958, 68, 50.

30. Taylor, W. Isolation of oxo-steroids under neutral conditions. Nature (Lond.) 1958, 182, 1735.

31. Haines, J. W., and Karnemaat, J. N. Chromatographic separation of the steroids of the adrenal gland in Methods of Biochemical Analysis, D. Glick, Ed. New York. Interscience Publishers, 1954, vol. 1, p. 171 .

32. Reich, H., Nelson, D. H., and Zaffaroni, A. Isolation of 17-hydroxycorticosterone from blood obtained from adrenal veins of dogs. J. biol. Chem. 1950, 187, 411.

33. Bush, I. E. Chromatography of steroids and sterols. Brit. med. Bull. 1954, 10, 229.

34. Romanoff, F. B., and Hunt, C. A. Detection of $\mathrm{C}_{21}$ glycerol side chain steroids on paper chromatograms. Endocrinology 1955, 57, 499.

35. Zaffaroni, A., and Burton, R. B. Identification of corticosteroids of beef adrenal extract by paper chromatography. J. biol. Chem. 1951, 193, 749.

36. Kritchevsky, D., and Kirk, M. R. Detection of steroids in paper chromatography. Arch. Biochem. 1952, 35. 346 .

37. Finkelstein, M., and Cox, R. I. Method for simultaneous estimation of pregnane 3 alpha, 17 alpha, 20 alpha-triol and pregnane- 3 alpha, 17 alpha, 20 alpha-triol-11-one in urine. Proc. Soc. exp. Biol. (N. Y.) 1957, 95, 297.

38. Cox, R. I. Separation, detection and estimation of C21 17: 20 dihydroxy-20-methyl-steroids. Nature (Lond.) 1958, 181, 638.

39. DeCourcy, C. A trichloracetic acid reagent for the detection of pregnane-3 alpha: 17 alpha: 20-triols on paper chromatograms. J. Endocr. 1956, 14, 164.

40. Zaffaroni, A. Absorption spectra of sulfuric acid chromogens obtained from adrenal steroids and related compounds. J. Amer. chem. Soc. 1950, 72, 3828.

41. Gandy, H. M. Characterization of $\mathrm{C}_{21}$ steroids in urine of normal children (abstract). Clin. Res. Proc. 1957, 5, 15.

42. Zaffaroni, A. Personal communication.

43. Romanoff, L. P., Seelye, J., Rodriguez, R., and Pincus, G. The regular occurrence of $3 \alpha$-allotetra- hydrocortisol $(3 \alpha, 11 \beta, 17 \alpha-21$-tetrahydroxy-allopregnan-20-one) in human urine. J. clin. Endocr. 1957, 17, 434.

44. Bush, I. E., and Willoughby, M. The excretion of allotetrahydrocortisol in human urine. Biochem. J. 1957, 67, 689.

45. Lieberman, S., Mond, B., and Smyles, E. Hydrolysis of urinary ketosteroid conjugates. Recent Progr. Hormone Res. 1954, 9, 113.

46. Saba, N.. Hechter, O., and Stone, D. The conversion of cholesterol to pregnenolone in bovine adrenal homogenates. J. Amer. chem. Soc. 1954, 76, 3862.

47. Hechter, O., and Pincus, G. Genesis of adrenocortical secretion. Physiol. Rev. 1954, 34, 459.

48. Mason, A. S. Adrenal virilism: Abnormal response to ACTH. Proc. roy. Soc. Med. 1951, 44, 162.

49. Christy, N. P., Wallace, E. Z., and Jailer, J. W. The effect of intravenously-administered ACTH on plasma 17, 21-dihydroxy-20-ketosteroids in normal individuals and in patients with disorders of the adrenal cortex. J. clin. Invest. 1955, 34, 899.

50. Wilkins, L., Klein, R., and Lewis, R. A. Response to $\mathrm{ACTH}$ in various types of adrenal hyperplasia in Proceedings of the First Clinical ACTH Conference, J. R. Mote, Ed. Philadelphia, Blakiston Co.. 1950, p. 184.

51. Touchstone, J. C., Bulaschenko, H., Richardson, E. M., and Dohan, F. C. The excretion of pregnane-3 alpha, 17 alpha, 21-triol 20-one (tetrahydro S) in normal and pathologic urine. J. clin. Endocr. 1957, 17, 250.

52. Romanoff, L. P., and Wolf, R. S. The fractionation of corticosteroid metabolites in human urine. Recent Progr. Hormone Res. 1954, 9, 337.

53. Hechter, O., Zaffaroni, A., Jacobsen, R. P., Levy, H., Jeanloz, R. W., Schenker, V., and Pincus, G. The nature and the biogenesis of the adrenal secretory product. Recent Progr. Hormone Res. 1951, 6, 215.

54. Richardson, E. M., Touchstone, J. C.. and Dohan, F. C. Urinary alpha-ketolic steroid metabolites of cortical hormones administered to subjects with adrenal cortical insufficiency. J. clin. Invest. 1955, 34, 285.

55. Touchstone, J. C., Richardson, E. M., Bulaschenko, H., Landolt, I., and Dohan, F. C. Isolation of pregnane-3-alpha, 17-alpha, 21-triol 20)-one (tetrahydro compound $\mathrm{S}$ ) from the urine of a woman with metastatic adrenocortical carcinoma. J. clin. Endocr. 1954, 14, 676.

56. Rosselet, J. P., Overland, L., Jailer, J. W., and Lieberman, S. Die Isolierung von 3-alpha, 17 alpha, 21 trioxy-pregnanon-(20) (THS) aus menschlichem Harn. Helv. chim. Acta 1954, 37. 1933

57. Bricaire, H., Graveleau, J., and Laudat, P. Un nouveau cas d'hyperplasie congénitale des surrénales à forme hypertensive: Isolement du compose "S." Ann. Endocr. (Paris) 1958, 19, 725. 
58. Bergenstal, D. M., Huggins, C., and Dao, T. L.-Y. Metabolic effects of adrenalectomy in man in Ciba Colloquia on Endocrinology, G. E. W. Wolstenholme and M. P. Cameron, Eds. Boston, Little, Brown and Co. 1955, vol. 8, p. 415.

59. Thorn, G. W., Laidlaw, J. C., and Goldfien, A. Studies on the sodium-retaining effect of adrenal cortical hormones in Ciba Colloquia on Endocrinology, G. E. Wolstenholme and M. P. Cameron, Eds. Boston, Little, Brown and Co. 1955, vol. 8, p. 343.

60. Birke, G. The effect of Reichstein's substance $S$ on the excretion of 17-ketosteroids. Acta Endocr. 1954, 15, 17.

61. Dorfman, R. I. Adrenocortical steroids in humans, Discussion by C. F. Marrian in Ciba Colloquia on Endocrinology, G. E. Wolstenholme and M. P. Cameron, Eds. Boston, Little, Brown and Co. 1955, vol. 8, p. 137.

62. Thorn, G. W., Howard, R. P., and Emerson, K., Jr. Treatment of Addison's disease with desoxycorticosterone acetate, a synthetic adrenal cortical hormone (abstract). J. clin. Invest. 1939, 18, 449.

63. Thorn, G. W., Howard, R. P., Emerson, K., Jr., and Firor, W. M. Treatment of Addison's disease with pellets of crystalline adrenal cortical hormone (synthetic desoxycorticosterone acetate) implanted subcutaneously. Johns Hopk. Hosp. Bull. 1939, 64, 339.

64. Ferrebee, J. W., Ragan, C., Atchley, D. W., and Loeb, R. F. Desoxycorticosterone esters. Certain effects in the treatment of Addison's disease. J. Amer. med. Ass. 1939, 113, 1725.

65. Rodbard, S., and Freed, S. C. The effect of desoxycorticosterone acetate on the blood pressure of the dog. Endocrinology 1942, 30, 365.

66. Perera, G. A., and Blood, D. W. Pressor activity of desoxycorticosterone acetate in normotensive and hypertensive subjects. Ann. intern. Med. 1947, 27, 401.

67. Davies, D. F., and Clark, H. E. A hypertensive syndrome with relative adrenal cortical overactivity. Circulation 1950, 2, 494.

68. Liddle, G. W., Island, D., Estep, H., and Tomkins, G. M. Modification of adrenal steroid patterns in man by means of an inhibitor of 11 beta-hydroxylase (abstract). J. clin. Invest. 1958, 37, 912.

69. Jenkins, J. S., Pothier, L., Meakins, J. W., and Nelson, D. H. Pharmacologic inhibition of steroid oxygenation in the 11-position in man and dog (abstract). Program, Fortieth Meeting of the Endocrine Society, 1958, p. 19. 